“C 2019 IEEE. Personal use of this material is permitted. Permission from IEEE must be obtained for all other uses, in any current or future media, including reprinting/republishing this material for advertising or promotional purposes, creating new collective works, for resale or redistribution to servers or lists, or reuse of any copyrighted component of this work in other works." 


\title{
Reduction of the Detent Force in a Flux- Switching Permanent Magnet Linear Motor
}

\author{
Jing Zhao, Member, IEEE, Quansong Mou, Keyu Guo, Xiangdong Liu, Member, IEEE, Jian Li, \\ Youguang Guo, Senior Member, IEEE
}

\begin{abstract}
In this paper, the detent force caused by the end effect in a flux-switching permanent magnet linear motor (FSPMLM) with 6 slots and 5 poles is investigated and reduced by two different methods. Firstly, the detent force is diminished by adjusting the position of end teeth of primary side and injecting compensation current into compensation windings wound around the end teeth. Based on the linear relationship between compensation current and compensation force, the proper compensation current is derived and analyzed. Then, to avoid the magnetic coupling between compensation windings and phase windings, a novel compensation module with independent magnet circuit is presented and attached to the primary side of FSPMLM. Thirdly, the two detent force reduction methods are compared with each other, and the compensation module is proved to be more effective. Finally, a prototype of FSPMLM with compensation modules is manufactured and tested to validate the proposed compensation method.
\end{abstract}

Index Terms-Flux-switching linear permanent magnet motor (FSPMLM), detent force, compensation coil, compensation module.

\section{INTRODUCTION}

$\mathrm{L}$ INEAR MOTORS possess several advantages such as rapid dynamic response, high precision, excellent reliability and quiet operation. Therefore, this kind of motor is greatly required in the occasions where linear motion is needed, such as rail transit, ropeless elevator, and electromagnetic launch [1-5]. However, for the applications demanding extremely long secondary, such as rail transit and ropeless elevator, the conventional permanent magnet linear synchronous motor (PMLSM) is inappropriate, because large amount of expensive permanent magnets or copper windings are indispensable. Flux-switching linear permanent magnet motor (FSPMLM) is more appropriate for the long secondary occasions, because its permanent magnets and windings are all installed in the primary side. Its secondary side only consists

Manuscript received November 29, 2018; revised by March 31, 2019; accepted May 1, 2019; This paper was supported by the Intelligent Equipment and Technology of Automation Research and Development Platform under Grant 2016F2FC007. (Corresponding author: Xiangdong Liu.)

J. Zhao, Q. Mou, X. Liu and J. Li are with the School of Automation, Beijing Institute of Technology, Beijing, 10081, China. (e-mail: zhaojing_bit@bit.edu.cn; 2120170931@bit.edu.cn; xdliu@bit.edu.cn; yellowlightlee@163.com).

$\mathrm{K}$. Guo is with the Institute of Electrical Engineering of the Chinese Academy of Sciences, Beijing, 100190, China. (e-mail: guoky93@126.com).

Y. Guo is with the School of Electrical, Mechanical and Mechatronic Systems, University of Technology Sydney, Ultimo, NSW 2007, Australia (email: Youguang.Guo-1@uts.edu.au). of iron core. FSPMLM incorporates the merits of both permanent magnet linear synchronous machine and reluctance switching motors, such as simple structure, high robustness and low cost [6-8]. However, FSPMLM suffers from large detent force caused by its end effect and double salient structure, which is detrimental to the machine's dynamic performance, position accuracy and can cause fluctuation and noise in operation [9].

As linear motors, FSPMLM and PMLSM both suffer from detent force, so some methods to reduce detent force used in PMLSM can also be used in FSPMLM. The existing methods can be classified into two types: one is the control strategies of machines [10-14], and the other is the optimization of the machine structure [15-30].

In [10], a disturbance compensation scheme is presented to suppress thrust ripple in repetitive motion using PMLSM. In [11], the detent force of a PMLSM is oppressed by injecting a momentous current into phase windings by using field oriented control method. In [12], an improved predict current control scheme is adopted to protect PMLSM from the disturbance caused by parameter variation and thrust ripple. In [13], harmonic currents are injected into phase windings to reduce the dominate thrust ripple in an FSPMLM. In [14], the instantaneous current is injected using the field-oriented control (FOC) method to counteract the thrust ripples. Although these methods are proved to be effective, the corresponding control system is perplexed.

Changing structure of end side is also widely used to reduce detent force both in FSPMLM and PMLSM. Addition of the auxiliary teeth and teeth notching are employed to reduce the detent force of PMLSM in [15-16], and auxiliary poles are installed on the end sides of PMLSM to reduce the detent force. In conventional PMLSM whose permanent magnets are located on the secondary, adjusting the end teeth length of primary is a typical method to diminish detent force [17-19]. However, this method is no longer suitable for FSPMLM due to its special structure [20]. The detent force caused by the end effect in FSPMLM can be reduced by adjusting the position of end teeth [20]. [21] comparatively researches the effects of two different types end teeth in a double-sided hybrid excited FSPMLM on thrust ripple. [22] shows that there is little difference between individual parameter optimization and genetic algorithm in optimizing FSPMLM, and the detent force can be reduced by adjusting the position and width of end teeth. [23] reduces the cogging force by slot effect of double-sided FSPMLM by asymmetry distribution of stator teeth, but the end effect is not taken into 
account. An FSPMLM topology with twisted stator is proposed in [24] and the optimal twisted angle is selected according to the cogging force, but the flux leakage between two stators is inevitable in spite of the existence of flux barrier. The idea of primary modularization is used both in the PMLSM [25] and in the FSPMLM [26] to reduce detent force. The width of teeth, height and width of PMs in a modular FSPMLM are optimized simultaneously to reduce detent force by using respond surface method in [27]. Multitooth is also a method to reduce cogging force and detent force in FSPMLM [28-29]. However, this method does not consider to combine the control strategy and structure optimization together.

[30] combines control strategy with structure optimization by skewing PMs in a PMLSM to suppress higher order harmonics in detent force and injecting harmonic current to suppress lower order detent force. [31] combines control strategy with structure optimization by winding two compensation coils on the end teeth of an arc-PMLSM. The detent force is suppressed by injecting compensation current into compensation coils, but the effectiveness of this method in FSPMLM needs to be further investigated.

In this paper, the reduction of the detent force in an FSPMLM is studied by using hybrid windings. First of all, the structure of a 6-slot and 5-pole (6s5p) FSPMLM is described and the detent force characteristic is investigated. Then the position of end teeth is adjusted to diminish the fundamental component in detent force. After that, the second order harmonic in detent force is reduced by injecting proper current into compensation winding wound around the end teeth. However, there is magnetic coupling between compensation windings and phase winding. Thus, a novel compensation module is proposed and investigated further. The effectiveness of compensation modules is compared with the compensation windings wound around end teeth. Finally, the prototypes of FSPMLM and the compensation modules are manufactured and tested to validate the proposed method.

\section{STRUCTURE OF FSPMLM AND ANALYSIS OF DETENT FORCE}

A 6s5p FSPMLM is studied in this paper, as shown in Fig. 1. The structure with short primary and long secondary is adopted. PMs and armatures are all located in the primary side. PMs are sandwiched between two adjacent U-shaped iron cores, while armatures are crammed into the slots. Two end teeth are attached to the end sides of primary. Parameters marked in Fig. 1 are listed in Table I.

The detent force of the FSPMLM calculated by finite element method (FEM) is shown in Fig. 2. It is obvious that the detent force is extremely large due to the end effect and slot effect, and it can be seen that the detent force fluctuates periodically with one pole pitch $\tau_{p}(12 \mathrm{~mm})$. Moreover, it is obvious from the spectrum of detent force shown in Fig. 2(b) that the fundamental component and the second order harmonic are much larger than other components. Therefore, the detent force can be depicted in mathematical expression as:

$$
f_{\text {detent }}=F_{\text {detent } 1} \cos \left(2 \pi \frac{x}{\tau_{p}}+\theta_{d 1}\right)+F_{\text {detent } 2} \cos \left(4 \pi \frac{x}{\tau_{p}}+\theta_{d 2}\right)
$$

where $\theta_{d 1}$ and $\theta_{d 2}$ are the phase offsets of the fundamental component and second order harmonic of the detent force, respectively, while $F_{\text {detent } 1}$ and $F_{\text {detent } 2}$ are their amplitudes.

Considering the extremely large detent force, a typical method to reduce fundamental component in detent force by adjusting the positions of two end teeth $\left(L_{a t}\right)$ is adopted in this part. Amplitude of fundamental component in detent force with different $L_{a t}$ is shown in Fig. 3. When $L_{a t}$ equals 12.25 $\mathrm{mm}$, the fundamental component reaches its minimum.

The detent forces and their FFT results before and after the adjustment of end teeth are shown in Fig. 4. It can be seen that the fundamental component in detent force decreases from the $2.8 \mathrm{~N}$ to $0.5 \mathrm{~N}$ by $82.14 \%$. However, the second harmonic is greatly amplified, from $2.2 \mathrm{~N}$ to $6.3 \mathrm{~N}$, which deteriorates the fluctuation unexpectedly. Hence, it is also imperative to diminish the second order harmonic in detent force.

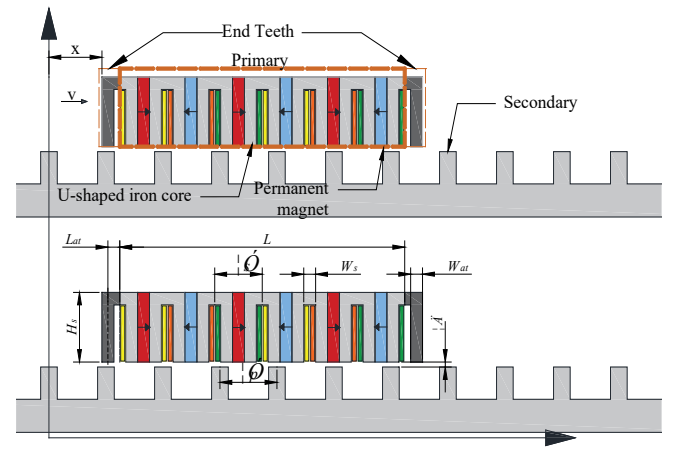

Fig. 1. Structure and important parameters of FSPMLM.

TABLE I

PARAMETERS OF THE FSPMLM

\begin{tabular}{ccc}
\hline \hline Quantity & Symbol & Values \\
\hline Supply voltage & $V_{\text {in }}$ & $12 \mathrm{~V}$ \\
Rated current & $I$ & $1.7 \mathrm{~A}$ \\
Number of phases & $m$ & 3 \\
Number of poles & $n_{p}$ & 5 \\
Number of slots & $n_{s}$ & 6 \\
Slot pitch & $\tau_{s}$ & $10 \mathrm{~mm}$ \\
Pole pitch & $\tau_{p}$ & $12 \mathrm{~mm}$ \\
Air gap & $\delta$ & $1 \mathrm{~mm}$ \\
Width of slot & $W_{s}$ & $2.5 \mathrm{~mm}$ \\
Height of primary & $H_{s}$ & $14 \mathrm{~mm}$ \\
Length of end tooth & $L_{a t}$ & $2.5 \mathrm{~mm}$ \\
Width of end tooth & $W_{a t}$ & $2.5 \mathrm{~mm}$ \\
Velocity of the primary & $v$ & $1240 \mathrm{~mm} / \mathrm{s}$ \\
Location of primary & $x$ & Changing with time \\
\hline \hline
\end{tabular}

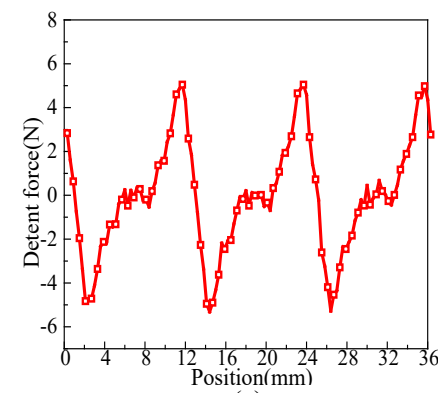

(a)

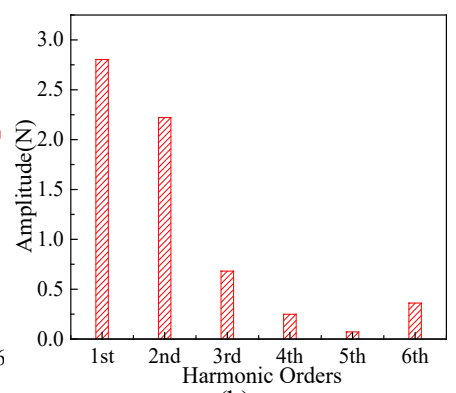

(b)

Fig. 2. Detent force without any compensation: (a) waveform of detent force, (b) spectrum of detent force. 


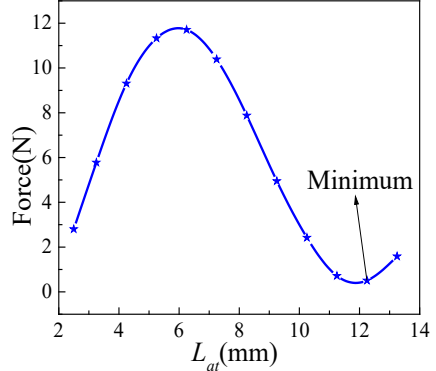

Fig. 3. Amplitude of fundamental component in detent force with different end tooth lengths.

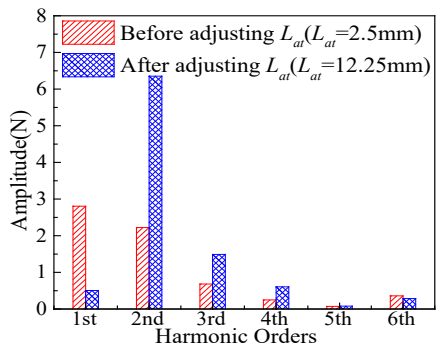

Fig. 4. Spectrum comparison between detent forces before and after adjusting $L_{a t}$.

\section{REDUCTION OF SECOND ORDER DETENT ForCE BY INSTALLING COMPENSATION WINDING}

\section{A. Principle of current compensation}

To reduce the second order harmonic detent force, two compensation windings are installed around the end teeth and a proper compensation current is injected, as shown in Fig. 5. The end teeth with the compensation coils work as electromagnets, which are able to provide the desired compensation force opposed to the second order harmonic in detent force with proper current. Taking the simplest case into account, a direct current of 1 A (1 ADC) is supplied into the compensation coils, the typical positions and the flux distributions of the primary/secondary are investigated and calculated by FEM, as illustrated in Fig. 6.

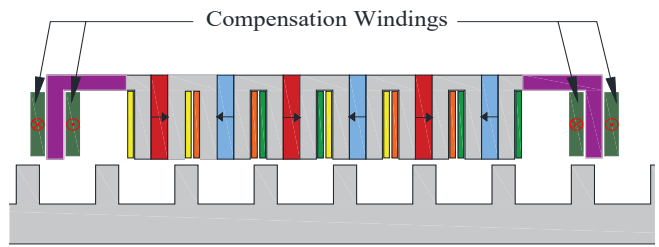

Fig. 5. Compensation windings installed on end teeth.

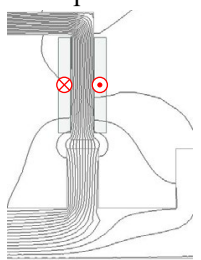

(a)

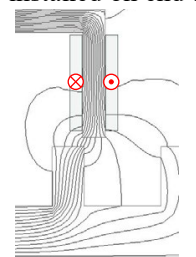

(b)

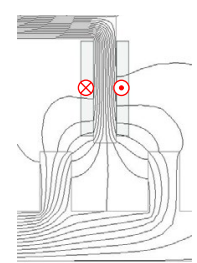

(c)

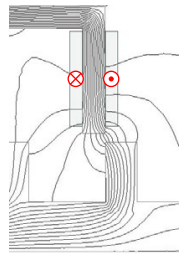

(d)

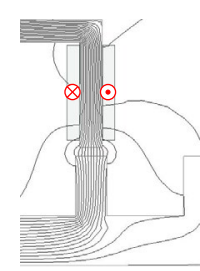

(e)
Fig. 6. Flux distributions at different positions of the primary/secondary.
In the position shown in Fig. 6 (a), the electromagnet faces to the secondary tooth directly, so the tangential force generated by $\mathrm{DC}$ is 0 . When the primary changes its position from (a) to (b), the tangential force reaches its maximum value because of the reluctance force. At position (c), the end tooth is right in the middle between the two secondary teeth, so the tangential force decreases to 0 again. The condition at position (d) is contrary to that at (b) and the tangential force generated by $\mathrm{DC}$ reaches its negative maximum. Moving from position (d) to position (e), which is the equivalent to (a), the tangential force returns to 0 again.

The detent force with DC in compensation coils is calculated by FEM. The force generated by 1 ADC can be obtained by subtracting the detent force without $1 \mathrm{ADC}$ from that with $1 \mathrm{ADC}$, as shown in Fig. 7. It can be seen that the force generated by DC varies periodically with a pole pitch (12 mm), which is consistent with Fig. 6.

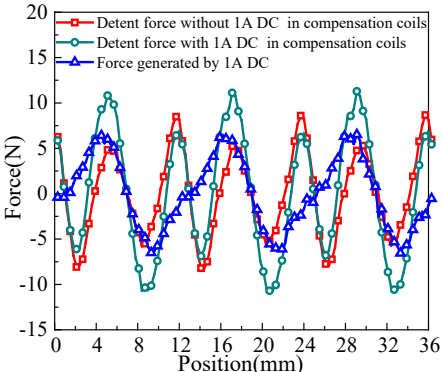

(a)

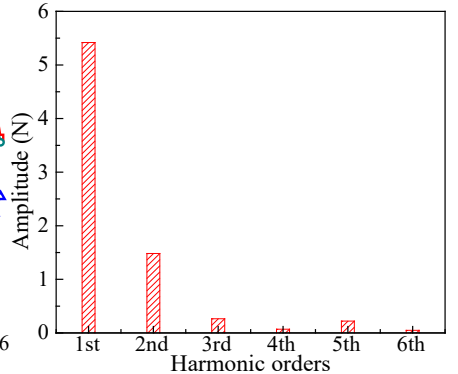

(b)
Fig. 7. The waveform and spectrum of forces: (a) the detent force with and without $1 \mathrm{ADC}$ as well as force generated by $1 \mathrm{ADC}$, (b) spectrum of force generated by $1 \mathrm{ADC}$.

According to the FFT result, the fundamental component and the second order harmonic in the compensation force are the main components. Thus, the force caused by $1 \mathrm{ADC}, f_{d c-1 \mathrm{~A}}$, can be approximately written as:

$$
f_{d c_{-} 1 A}=F_{d c_{-} 1 A} \cos \left(2 \pi \frac{x}{\tau_{p}}+\theta_{d c_{-} 1 A}\right)+F_{d c_{-} 1 A}{ }^{\prime} \cos \left(4 \pi \frac{x}{\tau_{p}}+\theta_{d c_{-} 1 A}{ }^{\prime}\right)
$$

where $F_{d c_{-} l A}$ and $\theta_{d c_{-} l A}$ are the amplitude and phase of the fundamental component in compensation force generated by 1 ADC, respectively. $F_{d c_{-} l A}$ ' and $\theta_{d c_{-} l A}$ 'are the amplitude and phase of the second order harmonic in the compensation force generated by $1 \mathrm{ADC}$, respectively.

It is well known that the force is proportional to the exciting current in permanent magnet motors when saturation does not occur. To obtain a compensation force contrary to the second order harmonic of detent force, according to homogeneous theorem, an alternating current (AC) with the same frequency of the fundamental force generated by DC is applied to the compensation coil, namely:

$$
i_{c}=I_{c} \cos \left(2 \pi \frac{x}{\tau_{p}}+\theta_{i c}\right)
$$

where $I_{c}$ and $\theta_{i c}$ are the amplitude and initial phase of the $\mathrm{AC}$, respectively.

Because of the linear relationship between compensation current and compensation force, the force generated by $\mathrm{AC}$ compensation current can be calculated as the product of $i_{c}$ and $f_{d c_{-} 1 A}$ : 


$$
\begin{aligned}
f_{c} & =i_{c} \times f_{d c_{-} 1 A} \\
& =\frac{1}{2} I_{c} F_{d c_{-} 1 A}\left[\cos \left(4 \pi \frac{x}{\tau_{p}}+\theta_{i c}+\theta_{d c_{-} 1 A}\right)+\cos \left(\theta_{i c}-\theta_{d c_{-} 1 A}\right)\right] \\
& +\frac{1}{2} I_{c} F_{d c_{-} 1 A^{\prime}}\left[\cos \left(6 \pi \frac{x}{\tau_{p}}+\theta_{i c}+\theta_{d c_{-} 1 A^{\prime}}\right)+\cos \left(2 \pi \frac{x}{\tau_{p}}-\theta_{i c}+\theta_{d c_{-} 1 A^{\prime}}\right)\right]
\end{aligned}
$$

As is seen from (4), there are accessional fundamental component and third order harmonic in $f_{\mathrm{c}}$ besides second order harmonic, which are caused by second order harmonic in $f_{d c \text { - }}$ 1A. These two unexpected components will distort the compensation force, and the effectiveness of the compensation current will be reduced. In order to minimize the second order harmonic in $f_{d c-1 \mathrm{~A}}$, the width of end teeth $\left(W_{a t}\right)$ is optimized.

$W_{a t}$ varies in the range of $2.5 \mathrm{~mm}$ to $6 \mathrm{~mm}$ by step of 0.5 mm. Fig. 8 exhibits the amplitude variation of different harmonics in $f_{d c_{-} I A}$ while $W_{a t}$ is changing. It can be seen that the amplitude of second harmonic declines firstly from $1.5 \mathrm{~N}$ to $0.02 \mathrm{~N}$ by $98.6 \%$ at $W_{a t}=5.0 \mathrm{~mm}$, and then rises. As for the amplitude of fundamental component, it reaches its maximum value when $W_{a t}$ equals $3.5 \mathrm{~mm}$ and is slightly larger than that with $W_{a t}=5.0 \mathrm{~mm}$. Thus, the end teeth with $W_{a t}=5.0 \mathrm{~mm}$ are selected. Then equation (4) can be simplified by neglecting the second order harmonic in $f_{d c-1 \mathrm{~A}}$ as:

$$
f_{c}=\frac{1}{2} I_{c} F_{d c_{-} 1 A}\left[\cos \left(4 \pi \frac{x}{\tau_{p}}+\theta_{i c}+\theta_{d c_{-} 1 A}\right)+\cos \left(\theta_{i c}-\theta_{d c_{-} 1 A}\right)\right]
$$

It is evident that there are no longer accessional harmonics in the compensation force. $\cos \left(\theta_{i c^{c}}-\theta_{d c_{-} l A}\right)$ is a constant value and will not affect the fluctuation in detent force.

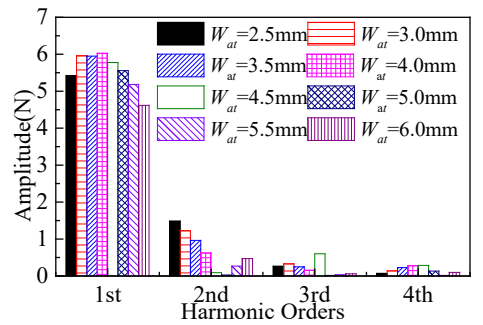

Fig. 8. Amplitudes of harmonics in $f_{d c_{-} I A}$ with different $W_{a t}$.

\section{B. Linearity check of compensation force generated by different $D C s$}

Equations (4) and (5) are based on the prerequisite that the compensation force has to be exactly or approximately proportional to compensation current. To check the linearity, different DCs are injected into the compensation windings and the corresponding forces generated by DCs are calculated. The forces generated by different DCs are shown in Fig. 9(a). And the relationship between amplitudes of forces and DCs is plotted as Fig. 9(b).

According to Fig. 9(b), the amplitude of the force generated by compensation current is not exactly proportional to the DC. This is because of the additional reluctance effect in the magnetic circuit of compensation winding, as shown in Fig. 10. This additional reluctance force can cause corresponding reluctance force which is proportional to the square of current. Hence, the practical compensation force is slightly larger than that with ideal linear relationship to DC (The red dashed line in Fig. 9(b)). However, the reluctance effect is weak when the compensation current is under $2.5 \mathrm{~A}$ (the deviation from the ideal force is less than $10 \%$ ), which can be linearized to ensure the equations (4) and (5).

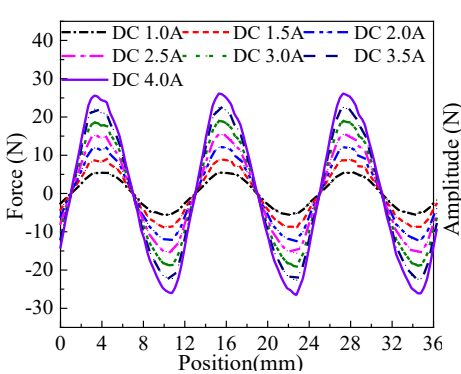

(a)

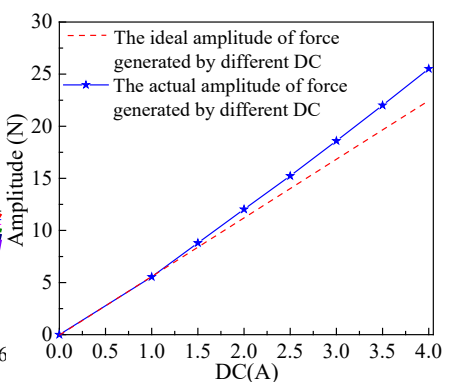

(b)
Fig. 9. The forces generated by different DCs: (a) the waveform, and (b) the amplitude.

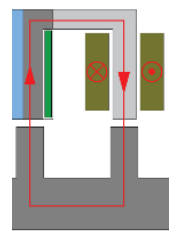

Fig. 10. Magnetic circuit of end teeth and compensation coils in FSPMLM.

\section{Second order detent force compensation}

Compare (1) with (5), it can be seen that the second order detent force can be eliminated if the following conditions are fulfilled:

$$
\left\{\begin{array}{l}
\theta_{i c}=\theta_{d 2}-\theta_{d c_{-} 1 A} \\
I_{c}=-\frac{2 F_{d e t e n t 2}}{F_{d c_{-} 1 A}}
\end{array}\right.
$$

The compensation AC is calculated according to (6) and injected into the compensation coils. The waveform of compensation current is shown in Fig. 11. The current has an amplitude of $1.9 \mathrm{~A}$ and fluctuates with a period of $12 \mathrm{~mm}$.

The compensation force generated by proper $\mathrm{AC}$ is shown in Fig. 12. It can be seen that the compensation force is contrary to the detent force. The detent forces before and after compensation are calculated by FEM and compared in Fig. 13(a). It can be seen that the peak to peak value of detent force decreases from $15 \mathrm{~N}$ to $4 \mathrm{~N}$ by $73.3 \%$ after the compensation $\mathrm{AC}$ is injected into the compensation coils. Moreover, the FFT result of the detent force is provided in Fig. 13(b), in which the second order harmonic is greatly suppressed.

The effectiveness of compensation current is also investigated in load condition. The thrust forces before and after compensation are shown in Fig. 14. It can be seen that the peak to peak value of thrust force is diminished noticeably, from $14 \mathrm{~N}$ to $6 \mathrm{~N}$ by $57.1 \%$. According to the spectrum of thrust force, it can be seen that the second order harmonic is also reduced a lot.

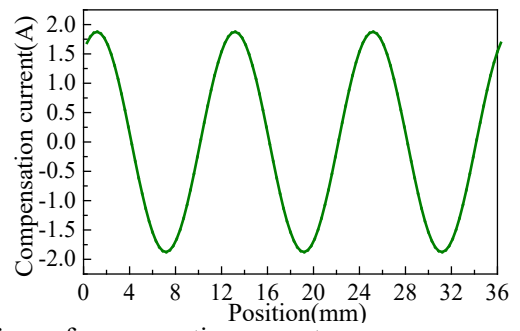

Fig. 11. Waveform of compensation current. 


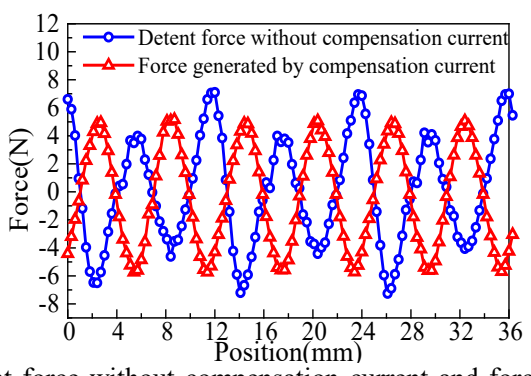

Fig. 12. Detent force without compensation current and force generated by compensation current.

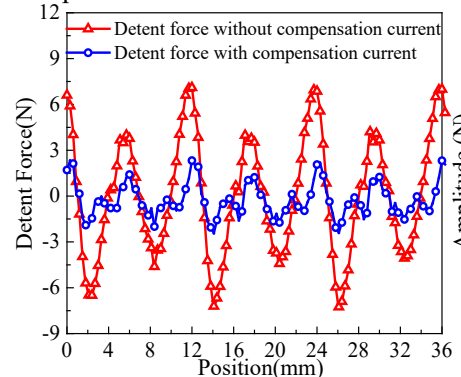

(a)

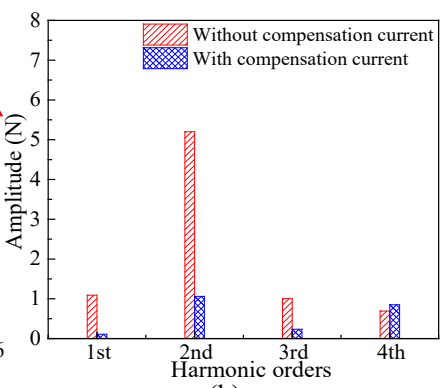

(b)
Fig. 13. Comparison of detent forces with compensation current and without compensation current: (a) waveform of detent force, and (b) spectrum of detent force.

However, there is magnetic coupling between compensation windings and phase windings, which can cause distortion in EMF of phase winding located at the end side of primary (also named as end phase in this paper), as shown in Fig. 15 (a). As shown in Fig.15 (b), the second order of EMF increases significantly after injecting compensation current to end tooth while the fundamental component decreases. The THD of EMF is $8.17 \%$ after injecting compensation current, which is much bigger than that before injecting compensation current $(2.23 \%)$. The distorted EMF interacts with the sinusoidal phase current which causes additional force ripple and has disadvantageous influence on compensation effectiveness. To solve these problems, a novel compensation method is proposed in the next section.

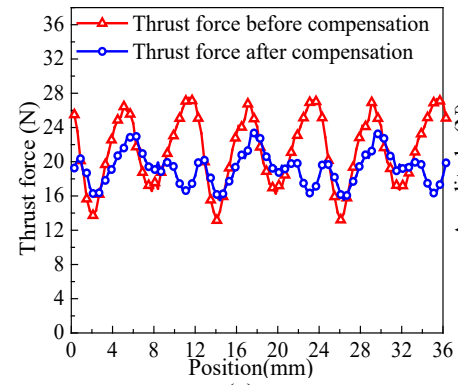

(a)

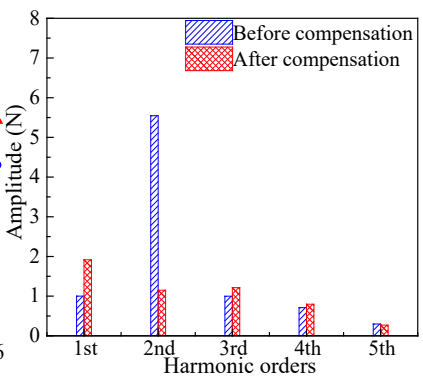

(b)
Fig. 14. Comparison of thrust forces with compensation current and without compensation current: (a) waveform of thrust force, (b) spectrum of thrust force.

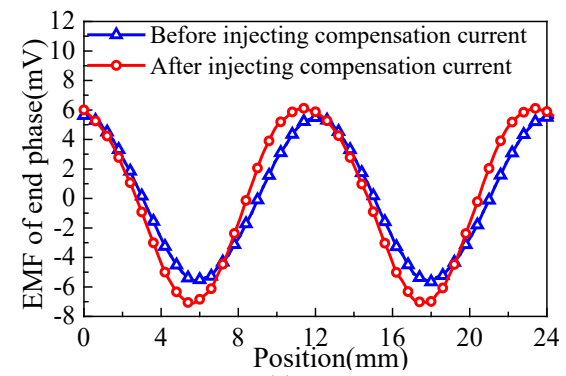

(a)

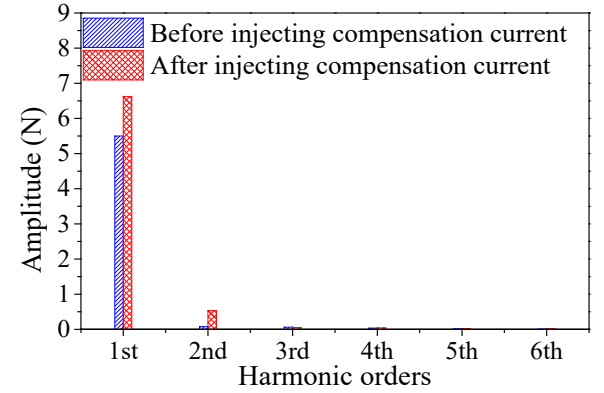

(b)

Fig. 15 Comparison of EMF before and after injecting compensation current: (a) waveforms of EMF, (b) spectrums of EMF.

\section{Comparison with adjusting end tooth length and width}

In order to better demonstrate the effectiveness of the method in reducing detent force, the end tooth length and width are optimized without compensation current. Firstly, $W_{a t}$ is set as $2.5 \mathrm{~mm}$ and relationship between detent force and $L_{a t}$ is shown in Fig. 16(a). As shown in the figure, when $L_{a t}=1.5$ $\mathrm{mm}$, the peak-peak value of detent force is the minimum with the value of $8.26 \mathrm{~N}$. Then $L_{a t}$ is set as $1.5 \mathrm{~mm}$ and the relationship between detent force and $W_{a t}$ is shown in Fig. 16(b). As shown in the figure, when $W_{a t}=2.7 \mathrm{~mm}$, the peakpeak value of detent force is the minimum with the value of 8.18N. As shown in Fig. 13, the detent force after optimizing end tooth and injecting compensation current is $4 \mathrm{~N}$, which is much smaller than that of only optimizing end tooth.

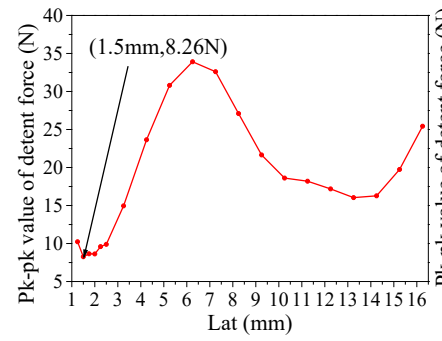

(a)

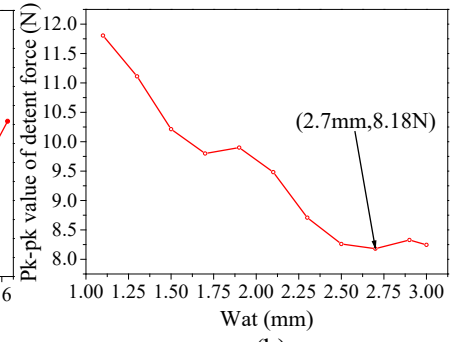

(b)
Fig. 16 Effect of $L_{a t}$ and $W_{a t}$ on detent force. (a) Relationship between detent force and $L_{a t}$. (b) Relationship between detent force and $W_{a t}$.

\section{REDUCTION OF DETENT ForCE BY COMPENSATION MODULE}

\section{A. Structure of compensation module}

To diminish the compensation current and weaken the influence of flux excited by compensation current on the EMF of end coils in FSPMLM, a novel compensation module is designed and installed on both end sides of motor primary through flux barrier, as shown in Fig. 17. The structure of compensation module is shown in Fig. 17(a). The compensation module consists of two iron teeth shaped as letter " $L$ ", an assistant permanent magnet sandwiched between the iron teeth and a compensation coil wound around the assistant PM and iron teeth. Some important parameters of the module are marked in Fig. 17(c) and listed in Table II. 


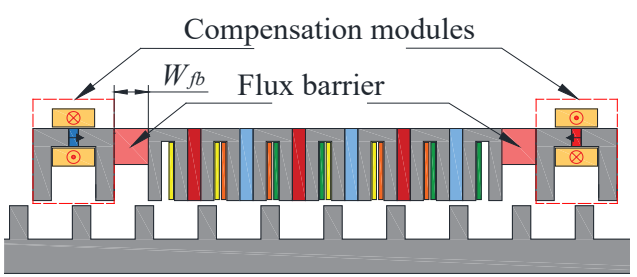

(a)

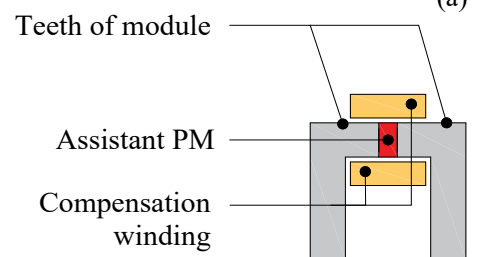

(b)

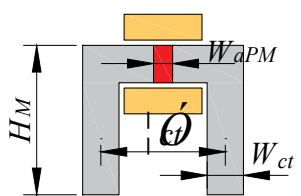

(c)
Fig. 17. Compensation modules: (a) compensation modules installed on primary, (b) structure of compensation module, (c) important parameters of compensation module.

TABLE II

PARAMETERS OF COMPENSATION MODULE

\begin{tabular}{ccc}
\hline \hline Quantity & Symbol & Values \\
\hline Height of compensation & $H_{M}$ & $14 \mathrm{~mm}$ \\
module & & $12 \mathrm{~mm}$ \\
Distance between module teeth & $\tau_{c t}$ & $3.5 \mathrm{~mm}$ \\
Width of module teeth & $W_{c t}$ & $1.0 \mathrm{~mm}$ (to be optimized) \\
Width of assistant PM & $W_{a P M}$ & $5.0 \mathrm{~mm}$ (to be optimized) \\
Width of flux barrier & $W_{f b}$ & \\
\hline \hline
\end{tabular}

B. Reduction of fundamental component in detent force by using PM in compensation modules

The detent force in FSPMLM without any compensation is already investigated in Section II, as shown in Fig. 2. To suppress the fundamental component in the detent force, two compensation modules without current in compensation coils are used. In order to simplify the analysis of the working principle, only one module is taken into consideration. The flux distributions at different positions of the compensation module/secondary are calculated by FEM, and the results are shown in Fig. 18.

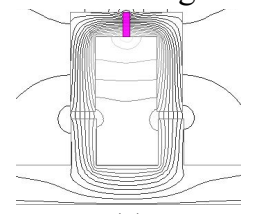

(a)

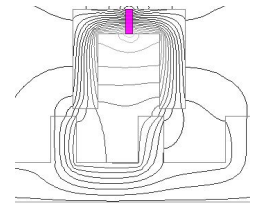

(b)

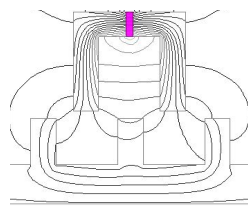

(c)

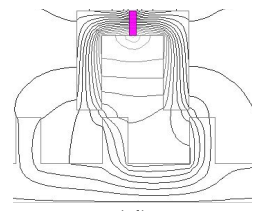

(d)

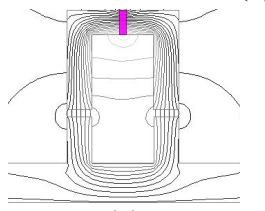

(e)
Fig. 18. Flux distributions at different position of the compensation module/secondary.

Similar to the end teeth shown in Fig. 6, the compensation modules utilize the reluctance force generated by interaction between assistant PMs and secondary teeth to compensate the fundamental component detent force. With different compensation module/secondary positions, the flux distributions are different. Similar to the compensation windings with $1 \mathrm{ADC}$, the $\mathrm{PM}$ in compensation module can generate a compensation force with period of $\tau_{p}$, expressed as:

$$
f_{a P M}=F_{a P M} \cos \left(2 \pi \frac{x}{\tau_{p}}+\theta_{a P M}\right)
$$

where $F_{a P M}$ is the amplitude of compensation force generated by assistant PM, while $\theta_{a P M}$ is the phase offset.

The compensation force generated by assistant PM in one single compensation module is plotted in Fig. 19. If the difference between the phase of tangential force generated by assistant PM and that of fundamental component in detent force equals $180^{\circ}$ and the amplitudes are equal, the fundamental wave in detent force can be eliminated. The proper $\theta_{a P M}$ can be obtained when the distance $W_{f b}$ between compensation modules and primary is equal to $6.5 \mathrm{~mm}$, which is obtained by adjusting the distance $W_{f b}$. The proper $F_{a P M}$ can be obtained by adjusting the width of assistant PMs $\left(W_{a P M}\right)$ in compensation modules. With $W_{a P M}$ changing from $0.5 \mathrm{~mm}$ to $1.0 \mathrm{~mm}$, the amplitude of the fundamental component in detent force after installing the two compensation modules firstly decreases and then rises up, reaching its minimum at $W_{a P M}=0.7 \mathrm{~mm}$, as shown in Fig. $20.0 .7 \mathrm{~mm}$ is selected as the thickness of assistant PM.

The detent forces with and without compensation modules are compared in Fig. 21(a), and their FFT results are displayed in Fig. 21(b). It can be seen that the amplitude of fundamental component in detent force is almost completely eliminated, i.e. from $2.71 \mathrm{~N}$ to $0.06 \mathrm{~N}$ by $97.7 \%$.

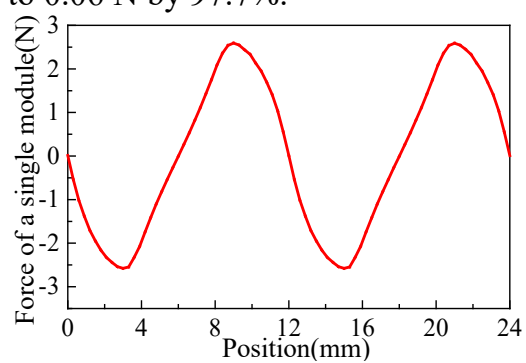

Fig. 19. Compensation force generated by assistant PM in compensation module.

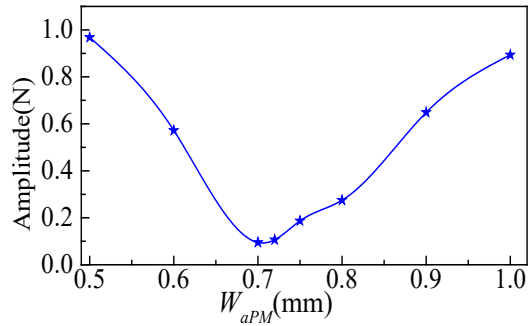

Fig. 20. The amplitude of fundamental component in detent force after installing the two compensation modules with various $W_{a P M}$.

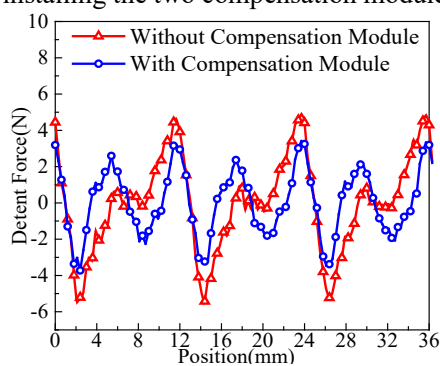

(a)

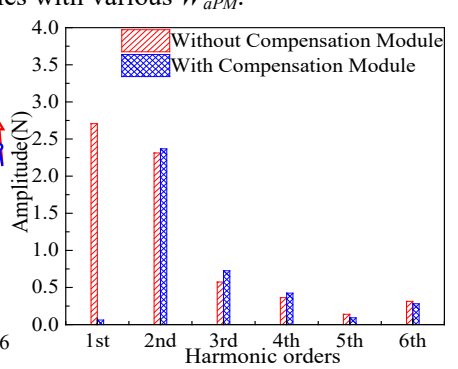

(b)
Fig. 21. Detent force before and after compensation: (a) the waveform of detent force, (b) the FFT result of the detent force. 
C. Reduction of second order harmonic in detent force by compensation current

Similar to the method in Section III, the second order harmonic in detent force can also be reduced by injecting a compensation $\mathrm{AC}$ with period of $\tau_{p}$ into the compensation windings wound on compensation modules, as shown in Fig. 22. The calculated compensation AC is shown in Fig. 23.

The detent force with the calculated compensation $\mathrm{AC}$ is calculated by FEM and compared to that without compensation AC, as in Fig. 24. It can be seen that the peak to peak value of detent force decreases from $7.19 \mathrm{~N}$ to $2.99 \mathrm{~N}$ by $58.4 \%$.

As for the load condition, the thrust fluctuation can also be suppressed, as illustrated in Fig. 25. After the installation of compensation modules and the injection of proper $\mathrm{AC}$ compensation current, it can be seen that the vibration of thrust force decreases greatly from $10.56 \mathrm{~N}$ to $3.92 \mathrm{~N}$ by $62.8 \%$.

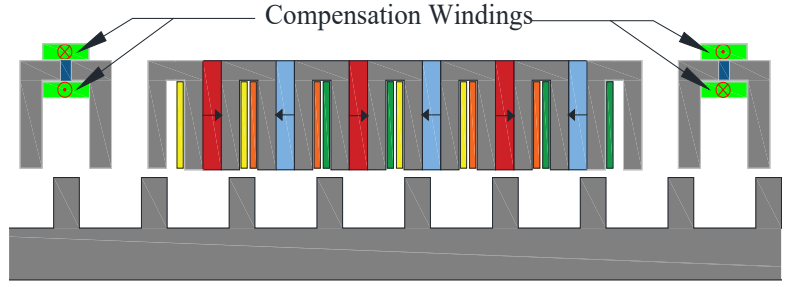

Fig. 22. Compensation modules with compensation coils.

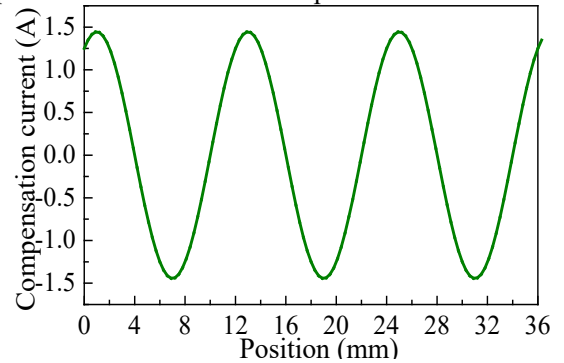

Fig. 23. Compensation current in compensation module.

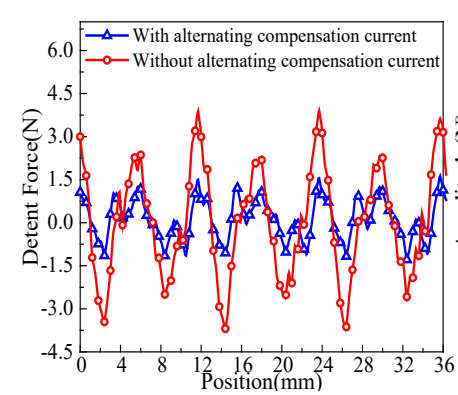

(a)

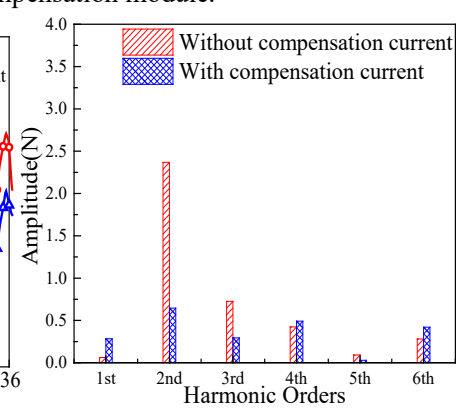

(b)
Fig. 24. Detent forces before and after the injection of compensation current: (a) waveform of detent force and (b) spectrum of detent force.

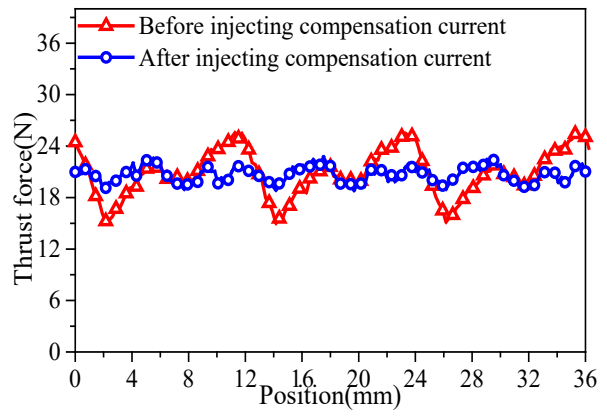

Fig. 25. Thrust forces before and after the injection of compensation current.

\section{Effectiveness of eliminating magnetic coupling}

In order to verify the effectiveness of compensation module in eliminating magnetic coupling, the EMF without compensation module and that with compensation module and current are compared. As shown in Fig. 26, the back EMF waveforms coincide basically in this two conditions and the harmonic components of the back EMF without and with compensation module and current remain basically unchanged. Besides, the THD of EMF is $2.25 \%$ with compensation module and current, which is little bigger than that without compensation module (1.93\%). The comparisons show that the compensation module and current have little effect on the back EMF.

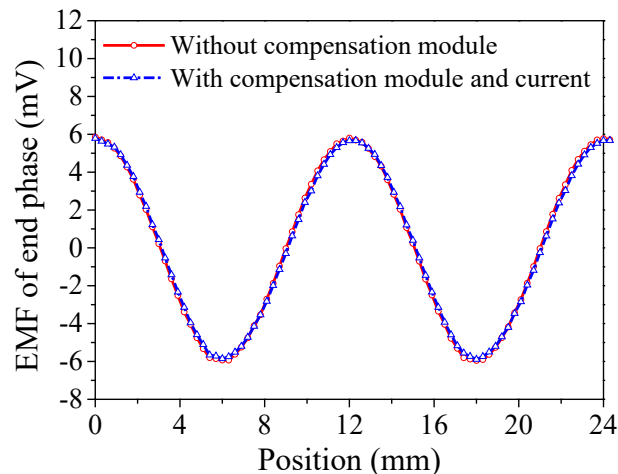

(a)

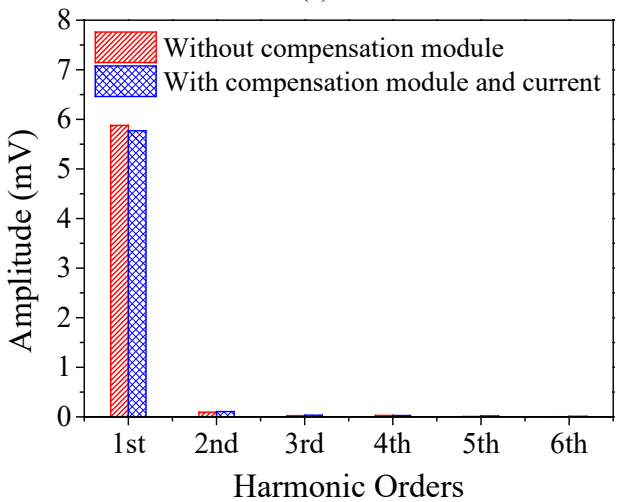

(b)

Fig. 26 Comparison of EMF without and with compensation module: (a) waveforms of EMF, (b) spectrums of EMF.

\section{COMPARISON OF THE TWO COMPENSATION METHODS}

In Section III, the detent force is diminished by additional teeth and the compensation windings (Method 1), while in Section IV, a novel structure with two compensation modules (Method 2) is utilized. Some parameters of these two methods and initial structure are compared in Fig. 27 and Table III. As shown in Fig.27 and Table III, both methods are effective for occasions with low thrust ripple and high positioning accuracy demand. The costs of FSPMLM optimized by these two proposed methods may be a little higher than that of initial structure. Compared with the effectiveness of decreasing the detent force, the extra cost is acceptable. Besides, compensation current inevitably increases the complexity of control strategy. However, position sensor is needed in both initial structure and optimized structures, these two methods will not much increase the difficulty of control. 
The length of primary in Method 2 is longer than that in Method 1, and the system cost with Method 2 may be higher than that with Method 1 . However, the compensation modules in Method 2 need 21\% smaller compensation current than Method 1. In addition, the detent force after compensation by method 2 is $25 \%$ lower than by Method 1 . That is to say, the compensation module is more effective. Moreover, in Method 1 , the fluxes generated by compensation coils will flow across the end coils through the additional teeth, which can affect the EMF. However, in Method 2, due to the modular structure and the flux barrier, the flux in compensation module is insulated, so the magnetic field between end phase windings and compensation windings is decoupled. In addition, this kind of compensation module can be used in linear motors with different structures, and its design and manufacture is simple. The proposed novel compensation module is a better choice to eliminate detent force in FSPMLM.

TABLE III

COMPARISON OF INITIAL STRUCTURE AND TWO COMPENSATION METHODS

\begin{tabular}{cccc}
\hline \hline Parameters & $\begin{array}{c}\text { Initial } \\
\text { structure }\end{array}$ & $\begin{array}{c}\text { Optimized } \\
\text { by Method1 }\end{array}$ & $\begin{array}{c}\text { Optimized } \\
\text { by Method2 }\end{array}$ \\
\hline Amplitude of compensation current & $0 \mathrm{~A}$ & $1.9 \mathrm{~A}$ & $1.5 \mathrm{~A}$ \\
Peak-peak value of detent force & $10.52 \mathrm{~N}$ & $4 \mathrm{~N}$ & $2.99 \mathrm{~N}$ \\
Average thrust at rated current & $22.1 \mathrm{~N}$ & $19.2 \mathrm{~N}$ & $20.6 \mathrm{~N}$ \\
Peak-peak value of thrust force & $10.56 \mathrm{~N}$ & $6 \mathrm{~N}$ & $3.92 \mathrm{~N}$ \\
Magnetic coupling with end phase winding & No & Yes & No \\
Whether need position sensor & Yes & Yes & Yes \\
Cost & Least & Lower & Higher \\
\hline
\end{tabular}

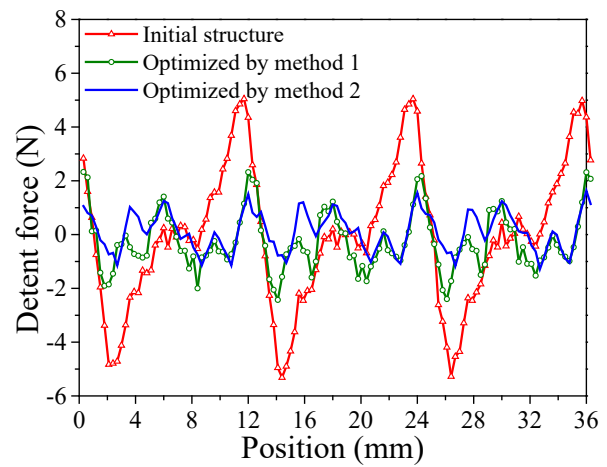

(a)

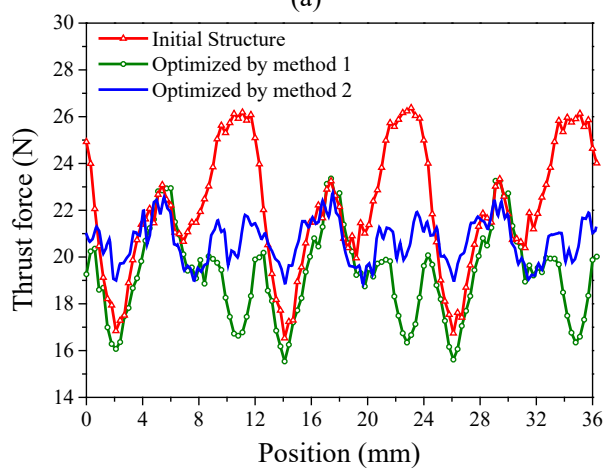

(b)

Fig. 27 Comparison among initial structure and after optimized by the two methods. (a) Detent force, (b) Thrust force..

\section{VALIDATION BY EXPERIMENT}

To validate the effectiveness of the proposed compensation module, a prototype of 6s5p FSPMLM with compensation modules is manufactured and the experimental setup is shown in Fig. 28. Because of the large machining errors (the width of secondary teeth is $0.5 \mathrm{~mm}$ larger than the designed one, the air gap is $0.5 \mathrm{~mm}$ larger than the designed one because of the machining error of secondary, and the surface roughness is much larger than the designed value), the models in FEM are recalculated according to the manufactured parameters.

The back-EMF is firstly measured and compared with the result of FEM, as shown in Fig. 29. The motor is driven by $12 \mathrm{~V} \mathrm{DC}$ and the rated speed is $1240 \mathrm{~mm} / \mathrm{s}$. The primary speed in the experiment is $496 \mathrm{~mm} / \mathrm{s}$, although the back EMF is lower than the rated one, it can be seen that the experiment is consistent with the simulation. Fig. 30 shows the detent force without compensation modules. It can be seen that the calculated results by FEM achieve good agreements with the measured results. The little difference between experiment and simulation is caused by mechanical friction of guide rail. To reduce the detent force further, the compensation module is installed and a proper compensation $\mathrm{AC}$ of $1 \mathrm{~A}$ is injected. It can be seen from Fig. 31 that the peak to peak value of detent force is reduced from $6 \mathrm{~N}$ to $2 \mathrm{~N}$. Hence, it can be verified that the proposed compensation module is effective.
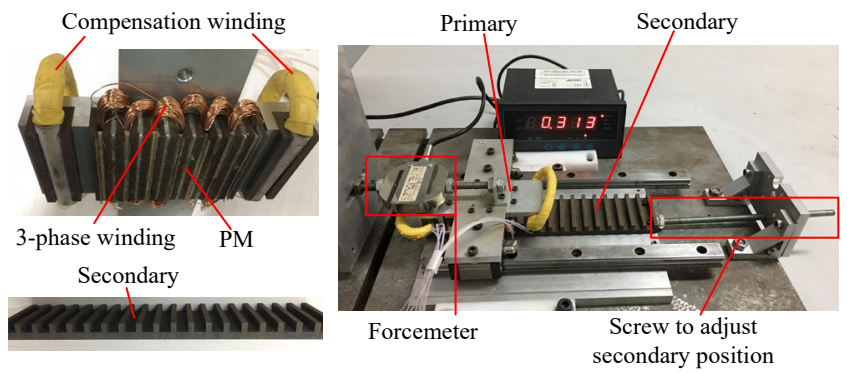

Fig. 28. Prototype and its experimental setup.

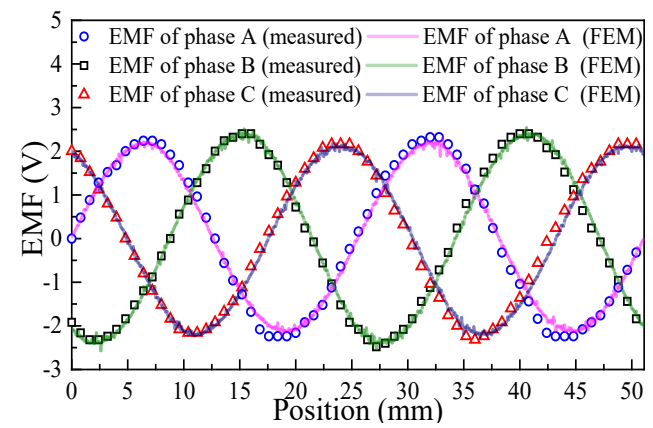

Fig. 29. Back-EMF of FSPMLM.

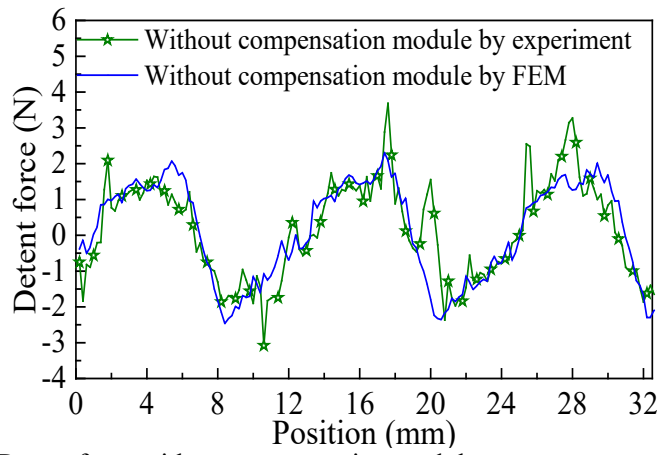

Fig. 30. Detent force without compensation modules. 


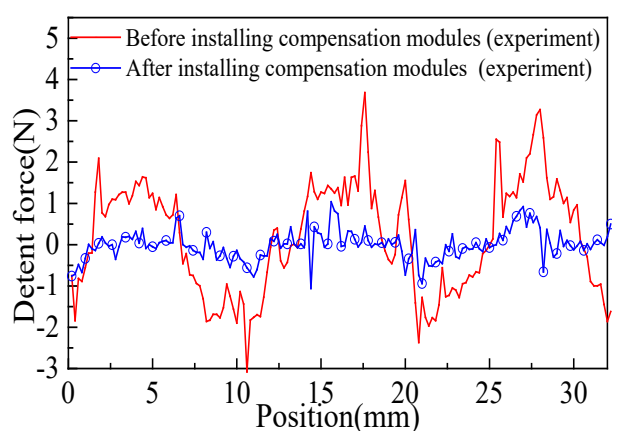

Fig. 31. Measured detent forces before and after injecting compensation current.

\section{CONCLUSION}

In this paper, the detent force of a $6 \mathrm{~s} 5 \mathrm{p}$ FSPMLM is reduced by two different methods, namely additional teeth with compensation windings (method 1) and compensation modules (method 2). In method 1, the fundamental component in detent force is diminished by adjusting the end teeth position of primary side, while the second order harmonic in detent force is suppressed by injecting compensation AC into compensation windings wound on the end teeth. The compensation current is derived and the linear relationship between compensation current and compensation force is checked. As the result, the detent force is reduced by $55.5 \%$. However, the compensation $\mathrm{AC}$ in compensation windings can cause back EMF distortion in the end phase coils of primary side because of the magnetic coupling. To avoid this problem, the compensation module is proposed and investigated in Method 2. The fundamental detent force is reduced by adjusting width of assistant PM in compensation modules, while the second order harmonic detent force is diminished by injecting compensation $\mathrm{AC}$ into compensation windings in compensation modules. The compensation current is obtained in the same way as Method 1. By using compensation modules, the detent force of FSPMLM can be reduced by $66.7 \%$. It is noted that compensation module is more effective in reducing detent force than the additional teeth with compensation windings. Moreover, the compensation current in compensation module is $20 \%$ smaller than that in windings on additional teeth. Prototype and experimental setup are established to validate the effectiveness of the proposed compensation module. Good agreements are obtained between the FEM and experimental results. According to the results of experiment using compensation modules, the peak to peak value of detent force is reduced from $6 \mathrm{~N}$ to $2 \mathrm{~N}$ by $67 \%$.

\section{REFERENCES}

[1] K. H. Shin, K. H. Kim, K. Hong, and J. Y. Choi, "Detent force minimization of permanent magnet linear synchronous machines using subdomain analytical method considering auxiliary teeth configuration," IEEE Trans. Magn., vol. 53, no. 6, pp. 1-4, June 2017.

[2] Y. W. Zhu, D. H. Koo and Y. H. Cho, "Detent force minimization of permanent magnet linear synchronous motor by means of two different methods," IEEE Trans. Magn., vol. 44, no. 11, pp. 4345-4348, Nov. 2008.

[3] Y. S. Kwon and W. J. Kim, "Detent-force minimization of double-sided interior permanent-magnet flat linear brushless motor," in IEEE Trans. Magn., vol. 52, no. 4, pp. 1-9, Apr. 2016.
[4] S. U. Chung and J. M. Kim, "Double-sided iron-core PMLSM mover teeth arrangement design for reduction of detent force and speed ripple," IEEE Trans. Ind. Electron., vol. 63, no. 5, pp. 3000-3008, May 2016.

[5] H. Zhang, B. Kou, Y. Jin, and H. Zhang, "Investigation of auxiliary poles optimal design on reduction of end effect detent force for PMLSM with typical slot-pole combinations," IEEE Trans. Magn., vol. 51, no. 11, pp. 1-4, Nov. 2015.

[6] D. C. J. Krop, L. Encica, and E. A. Lomonova, "Analysis of a novel double sided flux switching linear motor topology," in Proc. XIX Int. Conf. on Electrical Machines, Rome, 2010, pp. 1-5.

[7] S. E. Abdollahi and S. Vaez-Zadeh, "Back EMF analysis of a novel linear flux switching motor with segmented secondary," IEEE Tran. Magn., vol. 50, no. 4, pp. 1-9, Apr. 2014.

[8] A. Gandhi and L. Parsa, "Thrust optimization of a five-phase faulttolerant flux-switching linear synchronous motor," -in Proc. 38th Annual Conf. of IEEE Ind. Electron. Society, 2012, pp. 2067-2073.

[9] R. Cao, M. Cheng, and B. Zhang, "Speed control of complementary and modular linear flux-switching permanent-magnet motor," IEEE Trans. Ind. Electron., vol. 62, no. 7, pp. 4056-4064, July 2015.

[10] K. Cho, J. Kim, S. B. Choi, and S. Oh, "A high-precision motion control based on a periodic adaptive disturbance observer in a PMLSM," IEEE/ASME Trans. Mechatronics, vol. 20, no. 5, pp. 2158-2171, Oct. 2015.

[11] Y. W. Zhu, S. M. Jin, K. S. Chung, and Y. H. Cho, "Control-based reduction of detent force for permanent magnet linear synchronous motor," IEEE Trans. Magn., vol. 45, no. 6, pp. 2827-2830, June 2009.

[12] M. Wang, L. Li, D. Pan, Y. Tang, and Q. Guo, "High-bandwidth and strong robust current regulation for PMLSM drives considering thrust ripple," IEEE Trans. Power Electron., vol. 31, no. 9, pp. 6646-6657, Sept. 2016.

[13] S. Xu, W. Zhao, J. Ji, Y. Du, D. Zhang, and G. Liu, "Thrust ripple reduction of linear flux-switching PM motor using harmonic injected current," in Proc. Int. Conf. on Electrical Machines and Systems, Busan, 2013, pp. 1886-1889.

[14] Y. W. Zhu and Y. H. Cho, "Thrust ripples suppression of permanent magnet linear synchronous motor," IEEE Trans. Magn., vol. 43, no. 6, pp. 2537-2539, June 2007.

[15] S. W. Seo, G. H. Jang, M. M. Koo, and J. Y. Choi, "Characteristic analysis of the influence of auxiliary teeth and notching on the reduction of the detent force of a permanent magnet linear synchronous machine," IEEE Trans. Applied Superconductivity, vol. 28, no. 3, pp. 1-5, Apr. 2018.

[16] Y. W. Zhu, S. G. Lee, K. S. Chung, and Y. H. Cho, "Investigation of auxiliary poles design criteria on reduction of end effect of detent force for PMLSM," IEEE Trans. Magn., vol. 45, no. 6, pp. 2863-2866, June 2009.

[17] M. Inoue and K. Sato, "An approach to a suitable stator length for minimizing the detent force of permanent magnet linear synchronous motors," IEEE Trans. Magn., vol. 36, no. 4, pp. 1890-1893, Jul. 2000.

[18] J. Wang, M. Inoue, Y. Amara, and D. Howe, "Cogging-force-reduction techniques for linear permanent-magnet machines," IEE Proceedings Electric Power Applications, vol. 152, no. 3, pp. 731-738, May 2005.

[19] H. Z. Hu, X. D. Liu, J. Zhao, and Y.G. Guo, "Analysis and Minimization of Detent End Force in Linear Permanent Magnet Synchronous Machines," IEEE Trans. Ind. Electron., vol. 65, no. 3, pp. 2475-2486 March 2018.

[20] C. F. Wang, J. X. Shen, Y. Wang, L. L. Wang, and M. J. Jin, "A new method for reduction of detent force in permanent magnet fluxswitching linear motors," IEEE Trans. Magn., vol. 45, no. 6, pp. 28432846, June 2009.

[21] C. Liu, C. Hwang, P. Li, S. Hung and P. Wendling, "Design Optimization of a Double-Sided Hybrid Excited Linear Flux Switching PM Motor With Low Force Ripple," in IEEE Transactions on Magnetics, vol. 50, no. 11, pp. 1-4, Nov. 2014, Art no. 8102704.

[22] W. Min, J. T. Chen, Z. Q. Zhu, Y. Zhu and G. H. Duan, "Optimization of linear flux switching permanent magnet motor," 2010 IEEE Vehicle Power and Propulsion Conference, Lille, 2010, pp. 1-6.

[23] Q. Liu, et al., "Cogging force reduction of double-sided linear fluxswitching permanent magnet machine for direct drives," IEEE Trans. Magn., vol. 49, no. 5, pp. 2275-2278, May 2013.

[24] W. Hao, Z. Deng, and Y. Wang, "Cogging force reduction for the linear flux-switching permanent magnet machines based on a twisted stator," in Proc. 18th Int. Conf. Electrical Machines and Systems, Pattaya, 2015, pp. 1147-1150. 
[25] N. Xi, J. Yang, Y. Cheng, and S. Zhu, "'Detent force analysis and structure improvement of PMLSM," in Proc. Int. Conf. Consumer Electronics, Communications and Networks, XianNing, 2011, pp. 260263.

[26] R. Cao, M. Cheng, and W. Hua, "Investigation and general design principle of a new series of complementary and modular linear FSPM motors," IEEE Trans. Ind. Electron., vol. 60, no. 12, pp. 5436-5446, Dec. 2013

[27] B. Zhang, M. Cheng, R. Cao, Y. Du, and G. Zhang, "Analysis of linear flux-switching permanent magnet motor using response surface methodology," IEEE Trans. Magn., vol. 50, no. 11, pp. 1-4, Nov. 2014.

[28] Y. Shen, Q. Lu, H. Li, J. Cai, X. Huang, and Y. Fang, "Analysis of a novel double-sided yokeless multitooth linear switched-flux PM motor," IEEE Trans. Ind. Electron.s, vol. 65, no. 2, pp. 1837-1845, Feb. 2018.

[29] Q. Lu, H. Li, X. Huang, D. Ye, Y. Fang, and Y. Ye, "Investigation of double-sided multi-tooth switched-flux linear motor," in Proc. Int. Conf. Electr. Mach. Syst., 2015, pp. 237-242.

[30] M. Wang, L. Li, and D. Pan, "Detent force compensation for PMLSM systems based on structural design and control method combination," IEEE Trans. Ind. Electronics, vol. 62, no. 11, pp. 6845-6854, Nov. 2015.

[31] B. Li, J. Zhao, X. Liu, Y. Guo, H. Hu, and J. Li, "Detent force reduction of an arc-linear permanent-magnet synchronous motor by using compensation windings," IEEE Trans. Ind. Electron., vol. 64, no. 4, pp. 3001-3011, Apr. 2017

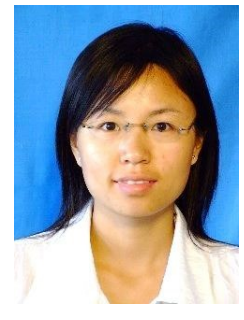

Jing Zhao (M'13) received the B.Sc. degree from Hebei University of Technology, Tianjin, China, in 2005, and the M.Sc., and Ph.D. degrees from Harbin Institute of Technology, Harbin, China, in 2007, and 2011, respectively, all in electrical engineering.

She is currently an Associate Professor Lecturer in the School of Automation, Beijing Institute of Technology, Beijing, China. Her research interests include electric machines and drive systems used for renewable energy and special servo machines system.

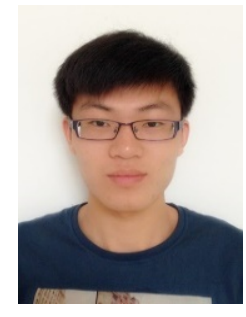

Quansong Mou received the B.E. degree from School of Automation, Beijing Institute of Technology, Beijing, China, in 2017. He is currently working toward the M.Sc degree in the school of Automation, Beijing Institute of Technology, Beijing, China.

His research interests include linear PM machines and new permanent magnet motor system.

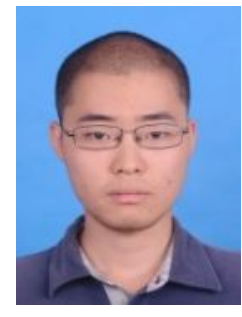

Keyu Guo was born in Beijing, China in 1993. He received the B.E. degree from Huazhong University of Science and Technology, Wuhan, China in 2015, the M.E. degree from Beijing Institute of Technology,Beijing, China in 2018.

$\mathrm{He}$ has been working towards the Ph.D.degree in Institute of Electrical Engineering, Chinese Academy of Science, Beijing, China since 2018, all in electrical engineering. His research interests include linear electrical machine design, optimization and control.

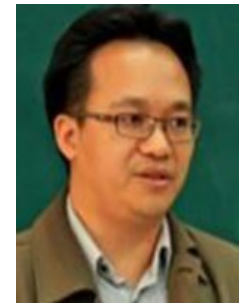

Xiangdong Liu (M'14) was born in 1971. He received the M.S. degree in electrical engineering and the Ph.D. degree in space engineering from Harbin Institute of Technology, Harbin, China, in 1995 and 1998, respectively.

$\mathrm{He}$ is currently a Professor in the School of Automation, Beijing Institute of Technology, Beijing, China. His research interests include high-precision servo control, motor drive control, piezoceramics actuator drives and compensation control, sliding control, state estimation, and attitude control.

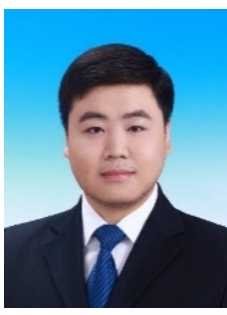

Jian Li received the B.E. and Master degrees in mechanical engineering from Beijing Technology and Business University, Beijing, China, separately in 2006 and 2010. He received the Ph.D. degree in mechanical engineering from Beijing Institute of Technology, Beijing, China in 2015.

$\mathrm{He}$ has been a Lecture with the School of Automation, Beijing Institute of Technology, since 2015. His research interests include modeling and design of Robotics and high-precision servo systems.

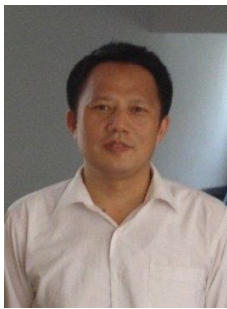

YouGuang Guo (S'02-M'05-SM'06) was born in Hubei, China in 1965. He received the B.E. degree from Huazhong University of Science and Technology, China in 1985, the M.E. degree from Zhejiang University, China in 1988, and the Ph.D. degree from University of Technology Sydney (UTS), Australia in 2004 , all in electrical engineering.

He is currently an associate professor at the School of Electrical, Mechanical and Mechatronic Systems, UTS. His research areas include measurement and characterization of magnetic properties of magnetic materials, numerical analysis of electromagnetic field, electrical machine design and optimization, power electronic drives and motor control. 